\title{
APONTAMENTOS: A REVISTA QUE NÃO EXISTE
}

\author{
Vera Lúcia Gainssa Balinhas* \\ Álvaro Veiga Júnior** \\ Álvaro Luís Ávila da Cunha***
}

RESUMO: O texto oferece aos/às leitores/as um processo simultâneo de produção de conhecimento e reinvenção do currículo. Ao relativizar ciência e cultura, concebendo a educação de maneira fluida, argumenta sobre a cientificidade de uma experiência político-pedagógica. O gesto de criação da revista Apontamentos permite desdobrar o espaçotempo pessoal e social; com isso, vem refletir sobre influências na subjetivação, construindo um texto amalgamado entre escrituras, buscando resistir criativamente às relações hegemônicas de poder. Teoriza seu fazer e seus percursos, compondo método em antinomia ética e estética com as posições que representam a verticalização do poder. A investigação projeta o currículo nas relações filosóficas entre o conhecimento e o cuidado de si, apoiando, prioritariamente, o estudo em Michel Foucault. Dentro dessa concepção, não haveria conteúdos pretendidos, separados das formas, da estética e de seu constituir, mas sim uma escritura conjugada em tempos e deslocamentos, vivência curricular construída com encontros em diferentes contextos e instituições educacionais, entre distintos grupos de professores/as e acadêmicos/as.

Palavras-chave: Currículo. Revista. Conhecimento. Cuidado de Si.

\footnotetext{
* Doutoranda em Educação pela Universidade Federal de Pelotas da Faculdade de Educação (UFPel-FaE); Vinculada à linha de pesquisa Currículo, Profissionalização e Trabalho Docente; Bolsista CAPES. E-mail: vera.balinhas@gmail.com

* * Mestre em Educação Ambiental; Professor-pesquisador do curso Licenciatura em Pedagogia a Distância da Universidade Federal de Pelotas (CLPD /UFPEL) e Mestrando em Educação pela Universidade Federal de Pelotas (UFPEL) e Pesquisador do Grupo Fepráxis. E-mail: avjsur@yahoo.com.br

Álvaro Veiga Junior

*** Doutor em Educação Ambiental pela Universidade Federal do Rio Grande (FURG-PPGEA); Professor Titular do curso de Licenciatura em Educação Física da Universidade Federal do Pampa (UNIPAMPA- Uruguaiana). E-mail: alvaro.balas@gmail.com
} 


\section{APONTAMENTOS: THE JOURNAL THAT DOES NOT EXIST}

ABSTRACT: The text offers the reader, simultaneously, knowledge production and curriculum reinvention. By relating science and culture to one another (letting their different standpoints influence one another), conceiving of education as a fluid process, it argues for the scientific validity of the political-pedagogical experience. The gesture of creating the journal, Apontamentos, allows the unfolding of a personal and social space-time; by doing so, it permits reflection on the influences involved in the process of subjectivity (allowing a personal experience and individual interpretation of events). It does so, by amalgamating the texts of various authors, in an attempt to resist hegemonic power relations, in a creative way. The process and the route are theorized to compose a method which is both ethically and aesthetically in opposition to hierarchical structures. The investigation lances the curriculum into a philosophical relationship between knowledge and the care of the self, which gains theoretical support from the work of Michel Foucault. Within this concept, there would be no intentional curricular content, separated according to its form (quality), nor of the aesthetic from the constitution (since it [the constitution] gives shape to the aesthetic experience of living), rather a journal of writing contributions, co-located (and conjugated) with reference to time and in spite of spatial separation (dislocation), hence a curricular living experience, built through the meeting of distinct groups of teachers and students, in different educational contexts and institutions.

Keywords: Curriculum. Journal. Knowledge. Care of the Self.

\section{Preâmbulo}

Há um jogo literário quando dizemos que a Apontamentos não existe. Uma tentativa de dar leveza e humor a estas narrativas, praticando na forma de escrever a concepção de que a linguagem não é precisa. $\mathrm{E}$ que talvez seja um grande equívoco querer que seja. Pretende-se, assim, relações entre linguagem e educação vigorosas, sem, contudo, capturar um modelo homogêneo de realidade. Desprender-se da obsessão por resultados objetivos e infalíveis, duvidar das pautas prescritas

No texto que segue, percorremos a experiência de criação de uma revista político-pedagógica, seu percurso e seu "desaparecimento", transformando-se em vivência curricular e busca de produção de conhecimento científico e cultural. Experiência construída por encontros em diferentes contextos e instituições educacionais e com distintos grupos de professores/as e acadêmicos/as.

Uma aventura que acreditava saber somente aonde não ir, e quis problematizar intensamente a abertura para relações entre pesquisa, edu- 
cação, estudo e ensino. Orientou-se por numa concepção formativa inacabada e contingente da existência. Talvez a revista tenha sido um dos efeitos do processo de pesquisa que a Constituinte Escolar do Estado buscava estabelecer, dinamizando e subjetivando a comunidade escolar, propiciando novos gestos curriculares.

Guiamo-nos por questões político-culturais, em antinomia ética e estética com as posições institucionais que representam a verticalização do poder. Aqui, ainda, procuraremos referenciar o estudo, junto com o currículo-formação, nas relações filosóficas entre o conhecimento e o cuidado de si, à maneira de Michel Foucault.

Ao querer criar uma revista, nós, educadores/as da rede pública estadual, pretendíamos ter a oportunidade de escrever sobre algumas vivências pedagógicas, experiências em educação e pesquisa, nossa visão acerca do mundo e a contradição da estrutura educacional, abarcando diversos estilos e linguagens.

Diante desse contexto, a experiência poderia ser pensada como mostra que se organizou, teorizou e se examinou, ou ainda como presença curricular, na medida em que são criações influenciadas e elaboradas na trajetória de professores-estudantes de cursos de mestrado em andamento na época e, nesse momento, alguns em doutoramento.

\section{Precedentes políticos e cotidianos}

Entre a revista Apontamentos, produzida por um grupo de professores/as da rede pública, e o movimento da Constituinte Escolar (CE), no início da década atual, desencadeado pela Secretaria de Educação do Estado do Rio Grande do Sul, existe uma relação de decorrência. Depois de intensos e polêmicos quatro anos de debates, dentro das instituições de ensino, tornou-se quase impossível para muitos/as educadores/as que vivenciaram tais momentos sujeitarem-se à falta de políticas públicas, no governo subsequente, que minimamente oportunizassem alguns projetos de formação continuada; negando às comunidades escolares a possibilidade de continuar participando da construção democrática da educação pública.

Foi assim, nessa falta de iniciativas governamentais, que surgiu a ideia de uma revista que reunisse aquelas experiências dos anos anteriores, que, se não transformou a educação, ao menos arranhou a estrutura edu- 
cacional hierárquica com pouca vocação para a democracia.

Mas, enfim, como significar a CE? Um instrumento de democracia direta e participativa? Espaço de lutas e conquistas para a melhoria da qualidade educacional? Construção coletiva de diretrizes para a educação? Movimento de formação política pedagógica da comunidade escolar? Ou mais uma política pública, de mais um governo, igual a tantas outras de tantos outros governos?

O significado da constituinte foi sendo construído e modificado junto ao processo. E essa construção, tijolo por tijolo, num desenho nada lógico, mostrou, de forma mais afirmativa, des-cobrin gigantescos muros existentes entre diferentes sujeitos da comunidade escolar: estudantes, profissionais em educação e família. Provenientes de formações culturais distintas e, muitas vezes, com interesses antagônicos, essas pessoas têm de, necessariamente, compartilhar um ambiente em que a ação de cada um repercute, direta e quase que imediatamente, no comportamento e no trabalho dos/as outros/as. Não é fácil transpor muros edificados por séculos em uma cultura hierárquica, moralista e autoritária; e, nas últimas décadas, intensificada por valores como a competição e o individualismo, característicos das sociedades urbanas industriais. Não é fácil, ainda mais sabendo que somos herdeiros/as dessa cultura. Criamos mecanismos de defesa, impedindo a aproximação do/a outro/a, uma vez que este/a virou inimigo/a. Ou seria nosso inferno, como anunciava Sartre? Logo, a sociedade da informação faz com que nos aproximemos e nos tornemos íntimos das máquinas chamadas inteligentes. Somos cada vez mais mediatizados, "A televisão me deixou burro, muito burro demais", dizia o rock brasileiro na década de 1980, e o urbanista francês Paul Virilio nos lembra do significado original de "estar mediatizado":

Até o século XX estar mediatizado significava literalmente estar privado de seus direitos imediatos. Desta forma o imperador Napoleão I mediatizava, no nível de suas conquistas militares, certos príncipes hereditários, privando-os de suas liberdades de ação e decisão ao lhes deixar as aparências de um poder que eles não estavam mais aptos a exercer (1996, p. 14-15).

A CE enfrentou essa lógica, apostando no encontro das pessoas com sua comunidade e apontando para a construção coletiva, senão de soluções imediatas, ao menos de referenciais para o enfrentamento desses problemas. 
Mais do que referenciais, conclusões e soluções, a CE oportunizou espaço para que mais vozes pudessem ser ouvidas. Essa participação talvez tenha sido uma novidade em políticas de formação continuada. Quem sabe já estejamos cansados de ouvir falar sobre participação popular e democracia. Pensamos inclusive que vivemos em democracia e podemos até concordar que nosso regime é democrático. Convém lembrar que a democracia nasceu em um estado escravagista, em que apenas uma casta participava das decisões políticas. Nossa democracia não se afastou muito dessa suposta origem, como podemos constatar na ligação mais que direta entre poder político e poder econômico.

Tanto a Lei de Diretrizes e Bases da Educação Nacional em vigor quanto os pareceres do Conselho Estadual e Federal de Educação oportunizam e estimulam práticas de autonomia escolar para definir suas normas de conduta (através do regimento) e seu currículo (projeto político-pedagógico e plano de estudos).

Inúmeras foram as possibilidades de transformação debatidas e construídas junto às comunidades escolares, tais como: romper com a hierarquia das disciplinas, democratizando a carga horária; flexibilizar a avaliação meramente quantitativa; buscar possibilidades interdisciplinares a partir de temas geradores; entender o conhecimento como construção e, por isso, a necessidade de estudarmos a partir da realidade local; garantir que, no currículo por atividade, a criança aprendesse com a atividade, através do jogo, do brinquedo, e não como tradicionalmente acontece, por área de conhecimento e até por disciplinas; simplificação da burocracia; romper com a emulação escolar, que reproduz a competição e o individualismo; reconfigurar o ensino noturno, aproximando-o da vida de estudantes jovens e adultos/as, valorizando a riqueza cultural dessas pessoas, não restringir o ensino médio ao vestibular e ao mercado, oportunizando a reflexão crítica da sociedade, apontando para formas cooperativas de trabalho; revitalizar as instâncias participativas da escola, como os conselhos e as assembleias comunitárias; participar da elaboração do orçamento estadual, reivindicando mais verbas para os setores sociais, via Orçamento Participativo.

O que teria ficado de todas essas possibilidades e tantas outras que surgiram nas discussões em salas de aula, ginásios, clubes, teatros, cozinhas, pátios e sala de professores, que reuniam mães, pais, funcionários/as educadores/as, estudantes, equipes diretivas e coordenações pedagógicas? 
Para nós, ficou a necessidade de continuar a construir maneiras cada vez mais abrangentes de formação, e uma certeza provisória de que a escola é um espaço de construção de conhecimento, e não mero campo de pesquisa utilizado pela ciência educacional ou campo de experimentação das universidades. Foi essa crença que nos permitiu imaginar uma revista produzida por aqueles/as, que no chão da escola, tentam, no seu labor profissional, inventar uma contraescola.

\section{Educação moderna:}

\section{breve contexto e algumas considerações}

Muitas vezes, a educação moderna pretendeu firmar critérios definitivos e verdadeiros sobre a formação humana. Acreditando numa essencialidade que se oporia à denominada barbárie, ao primitivismo, à selvageria, à loucura, ao outro, enfim, subsumida em processos missionários e salvacionistas. Com isso, pouco aprendemos sobre diferenças, e com um pensar de maneira mais horizontal e menos irradiador.

Atualmente, novas perspectivas teóricas vêm apontando para a falibilidade desse modelo e marcam os limites dos sistemas monoculturais. O processo de subjetivação e a produção de significados não podem ser represados, tampouco seus trajetos são progressivos e contínuos.

Embora entendendo que essa educação modelar permaneça carregada, saturada, centrada num discurso universalizante, persiste o desafio de posicioná-la diante dos impasses atuais. O que esperar das instituições que se inclinam a mediatizar e a contemporizar a vontade de mudanças? Como sopesar diferentes interesses, em contraste com um mundo limitado e existências finitas? Como se precaver das armadilhas do reproducionismo ou do experimentalismo2?

E, nesse sentido, ao pensar que a constituição existencial dos indivíduos, a profissionalização dos professores/as e de outros ofícios começam na vivência escolar, podemos imaginar a escola como um espaço-tempo mais propício às ações e relações humanas, apesar da rigidez institucional, das polarizações e setorizações herdadas. 


\section{Significação da revista: processo e produção}

Ao trilharmos a experiência curricular de construção dessa revista, nos aproximamos de variados aportes teóricos, nos arriscamos no jogo de aproximar teorizações críticas e pós-estruturalistas. Pensamos que o processo de constituição profissional, pessoal e estudantil negocia com as estruturas institucionais e, ao mesmo tempo, cria predisposições à abertura e à flexibilidade, produz resistências entre continuidades.

Assim, experimentamos e buscamos prosseguir a formação profissional em exercício, em contato com a escola e com outras instituições que se relacionam, direta ou indiretamente, com ela.

Poderia a Apontamentos ter assumido mais significados no percurso de divulgação? Produziria conhecimentos para além daquilo que percebíamos como produção de conhecimento? Que tipo de conhecimento? Aquele conhecimento advindo da separação hierárquica poderia ser (re)apropriado e socialmente válido e útil?

Dentro desse movimento, poderia ser compreendida mais, e ao mesmo tempo menos, que uma revista em si mesma, se traduziria em posições de professores/as e estudantes sem objetivos disciplinares ou institucionais. Ou quem sabe foi constituindo-se em um gesto simbólico, de insatisfação, de resistência, de identificação, "apesar de"? Dizemos "apesar de" frente a um posicionamento dicotômico otimista-pessimista, diante do paradigma da perfeição que caracteriza a modernidade.

"Apesar de", no decorrer da profissionalização, em muitos casos, ter-se a possibilidade de uma percepção na qual sujeito da formação inicial, na condição de estudante, foi pouco considerado no planejamento do currículo de ensino superior. E, não raro, quando os professores voltam às academias, como pesquisadores, têm as condições de possibilidades configuradas para lhes fazer voltar-se para a escola, desconsiderando as contribuições para as mudanças no ensino superior. Muitas vezes, esse ensino parece encastelado nas suas prerrogativas, na sua credibilidade metafísica, na sua operacionalidade cientificista.

Essa escola, que tem a potencialidade de ser um espaço-tempo privilegiado, uma instância social criadora, contrariamente a uma definição reducionista, sucumbe fácil e frequentemente, passando a ser um objeto, num sentido de abandono de suas possibilidades. 
Assim, entre as principais condicionantes, teríamos um tipo de ciência professada nas academias, responsáveis pela formação inicial dos professores/as, predominantemente de feitio disciplinar, nas licenciaturas ou na pedagogia. Cursos que não necessariamente tenham um currículo estático, eles vêm mudando, mas, substancialmente, têm sido reféns do academicismo. Parece que se pode dizer isso em um contexto maior, conforme, Giroux e MacLaren:

(...) $\mathrm{O}$ espaço político atualmente ocupado pela educação do professor em geral continua a diminuir a importância da luta pelo fortalecimento do poder docente; além disso, geralmente tem servido para reproduzir as ideologias tecnocráticas e corporativistas características das sociedades dominantes (2002, p. 128).

Parte da tradição hegemônica acadêmica corrobora para constituir a escola como transmissora de conteúdos científicos. Mas, como referimos anteriormente, conteúdos estes de uma ciência concebida pela influência iluminista, desmerecendo outras dimensões da existência humana. Essa característica da academia desvalorizaria também a educação que pratica, jactando-se em relação à prática de pesquisa de cunho tecnológico; privilegiando as ciências exatas e naturais, instrumentalizandoas para mover a tecnologia capitalista e industrial.

O primeiro contato institucional das gerações não teria valor político porque é considerado como uma simulação. Os profissionais permanentes da escola, por exemplo, podem praticar uma avaliação classificadora, punitiva ou premiativa, pois esse lugar ainda não seria o da vida real. Estudando historicamente relações de poder entre sociedade e escolarização, e a luta por uma significação da realidade, Goodson sugere que haja nisso uma continuidade estrutural:

A negociação contínua da realidade, tanto da parte dos indivíduos como parte dos grupos, revela as antecedentes estruturas de poder na educação e sugere a forma como as atitudes de grupos dominantes na sociedade continuam influenciando a escolarização, apesar dos sinais de conflitos e contestações. Os debates políticos, sociais, econômicos e culturais, tanto em torno das escolas como dos manicômios, têm sido tradicionalmente acalorados e causadores de distensões, ainda mais que a prática profissional tem-se mostrado acentuadamente resistente às mudanças (...) (1999, p. 132). 
A prática profissional, assim, tenderia a replicar o contexto hierárquico e elitista, por seu vínculo pouco explicitado com o contexto acadêmico. Nessa acepção, a ciência, nas suas vias institucionais, construiria dimensões do existir ou facetas hegemônicas da realidade, condicionando saberes e práticas. Teriam, assim, mais poder os conhecimentos ligados à tecnologia, às ciências ditas não humanas, dirigindo a formação profissional para o mercado vigente.

Considerando que a escola tem instituído seu currículo de forma disciplinar, ela é arco de um círculo que tem se perpetuado entre relações institucionais não muito claras. Incluindo no círculo a formação inicial para o magistério e o ensino básico, que são um dos atributos do estado. Assim, temos, no ensino superior público (e não só no público), as licenciaturas que preparam para campos disciplinares específicos: uma triagem por meio de vestibular disciplinar para licenciaturas disciplinares e, corolário, em uma escala correspondente, o currículo escolar em hierarquia disciplinar.

Havendo essa hierarquia de poderes entre disciplinas, tudo indica, advinda dos valores que pairam na academia, no mercado e no estado, praticamente é determinada a presença numérica de cada área no currículo escolar. É muito frequente, por exemplo, currículos com uma hora semanal de geografia, história e artes, em contraste com três a cinco horas de matemática, física, química e, só nos últimos anos, a sociologia e a filosofia estão sendo implementadas no currículo. Repetindo a estrutura universitária, que lhe corrobora uma credibilidade autocrática.

A dimensão institucional da educação, sistematizada, prevista nos ditames do estado-nação, atravessou gerações, entranhou-se, naturalizou-se invisivelmente, de tal forma, que pouco dá margem ou abertura para a multiplicidade cultural, esvazia as relações políticas e então não é mais possibilidade, momento ou projeto.

Dessa maneira, a configuração da escola estaria associada à ciência e à tecnologia, se entendidas como motor evolutivo, promotoras de progresso e contra outras tradições e culturas. Mas, na prática, produz uma lição de espera e docilidade que supervaloriza os processos regimentais e normativos para constituição dos papéis e autoridades. E, assim, exerceria uma pedagogia do exemplo de tradição iconoclasta, desmerecedora da sabedoria, das vivências milenares e do conhecimento aliado às culturas de si, estando em jogo o processo de subjetivação. 


\section{Produção de conhecimento: currículos e subjetividades}

Pensamos a experiência curricular da revista Apontamentos trilhando os caminhos do cuidado, da reflexão, da linguagem como criação e reinvenção de si. Buscando nas palavras escritas e lidas sentidos e significados, formas de sentir diferente, um olhar distraído e desarmado que se lança no jogo das palavras, toca e inspira outras experiências; uma procura que tematiza relações entre currículo e cultura. Trama que resulta conhecimento e, situado historicamente, embate-se por cientificidade nas aberturas e restrições da ciência e da filosofia.

Dentro dessa perspectiva, o currículo se constitui como prática social, como prática cultural, como prática de significação (SILVA, 2003), perpassa os acontecimentos educacionais dentro e fora dos espaços institucionais e se associa à fabricação de diferentes posições de sujeito.

Ao tratar do cuidado de si, o filósofo francês Michel Foucault parece marcar seu interesse em focalizar e examinar a constituição do sujeito: “(...) não é o poder, mas o sujeito que constitui o tema geral da minha pesquisa” (1995, p. 232). As investigações do poder, do saber e da ética estariam implicadas com processos de subjetivação, ocupadas em entender como o indivíduo se transforma em sujeito; abordam o cuidado de si como práticas sociais vivenciadas pela combinação de prescrições, proibições e prazeres que se movimentam, modificam no espaço-tempo. Ou, ainda, como produções, elaborações, ações, investimentos em si (cuidados com saúde, lazer, exercícios, meditações, reflexões), essas diferentes formas de agir sobre si foram definidas como tecnologias. Elas, as tecnologias, são analisadas através de dois princípios morais: cuidar-se e conhecer-se.

Não temos, assim como o autor, o interesse em traçar uma história linear, evolutiva, homogênea e reveladora da verdade do cuidado de si, mas sim trazer deslocamentos desses conceitos, sua história descontínua, confusa e construída. E, por conseguinte, teorizar a constituição de subjetividade, nas relações individuais ou não, procurando uma contextualização ética e estética de mundo. O caminho da experiência para a cientificidade se utiliza de atravessamentos filosóficos, nos quais os critérios referenciais se opõem ao cientificismo.

O cuidado de si, como preocupação e ocupação consigo, constituiu um princípio, um acontecimento, uma singularidade do pensamento 
que se estendeu à cultura grega, helenística e romana do século V a.C. até o V. d.C. (FOUCAULT, 2006). Esse preceito, algumas vezes, se separa e se embaralha com o conhecimento de si-marcado pelo caráter prescritivo, por regras que orientam as formas corretas de condução da vida e dos corpos.

Para o autor, esses dois princípios estavam mais vinculados na Antiguidade, mas o cuidado de si era mais prestigiado que o princípio délfico conbece-te a ti mesmo.

A verdade de ser um sujeito e a procura de uma ética da existência era principalmente, na Antiguidade, um esforço para afirmar a própria liberdade e de dar a sua própria vida uma certa forma na qual poderia se reconhecer e ser reconhecido por outros e onde a posteridade mesma poderia encontrar como exemplo (FOUCAULT, 2006, p. 231).

$\mathrm{Na}$ Antiguidade, o cuidado do outro estava relacionado com o cuidado de si: para cuidar a cidade, governar, era preciso saber governar-se. Com o cristianismo a negação de si, dos desejos, das paixões, das vontades (presente de certa forma e anteriormente, na filosofia estoica), passa a ser pressuposto para cuidar do outro, encontrar Deus e alcançar a salvação da alma. A ciência moderna inventa o sujeito epistemológico, diferencia conhecimento verdadeiro do falso, indica a melhor forma de conduzir-se através do conbecimento de si.

O outro do egoísmo passou a ser a renúncia "seja sob a forma cristã de uma obrigação e de um renunciar a si [por um Deus]. Seja sob a forma moderna de uma obrigação para com os outros quer o outro, quer a comunidade, quer a pátria, etc.” (FOUCAULT, 2006, p. 17).

Compreendemos que, na contemporaneidade, os cuidados de si e dos outros não estão alheios ao conhecimento da ciência de referência (uma verdade científica), tampouco aos preceitos cristãos (uma verdade religiosa). Eles, os cuidados, estão enredados em uma vasta diversidade de condições, incluindo os apelos midiáticos e comerciais do mercado capitalista.

Nossa formação, na maioria das vezes, está associada aos investimentos pessoais. Para tanto, não raramente, horas de lazer, descanso e até mesmo recursos econômicos são disponibilizados para esse fim. A falta de comprometimento do estado e as políticas neoliberais são evidenciadas em posturas dos representantes oficiais da educação. 
Muitas vezes, as representações da sociedade sobre a docência estão circunscritas à reprodução de informações. A fabricação de conhecimentos e saberes aparece restrita ao campo dos/as pesquisadores/as e dos teóricos da educação. Essa concepção dicotomizadora acompanha a maioria das políticas em educação; nossa tarefa seria repetir conceitos, ideias, técnicas, práticas, conhecimentos validados pela ciência de referência. No entanto, isso não satisfaz, pelo menos nesse espaço-tempo da revista, e para esse grupo de professores/as.

Nesse sentido, a revista Apontamentos, as escrituras sobre as experiências pedagógicas em educação e as contradições da estrutura escolar foram se aproximando de Foucault, dos estudos sobre o cuidado de si/cuidado do outro.

Estimamos que, por meio do processo reflexivo da leitura e da escrita, modificaríamos a prática educativa, nos tornando diferentes, compartilhando com colegas não somente experiências, mas também a constituição docente.

Seguimos envolvidos/as com os processos educativos, disputando significados, algumas vezes, em espaços rigorosamente fechados, fortemente marcados pelas tradições pelo peso das instituições. E, nesses momentos...

(...) é preciso esquecer, para poder continuar a edificar escolas, programas e pedagogias, mas, também como uma dessas dissonâncias que, em certos momentos, talvez seja preciso escutar ainda, para que o ato de ensinar jamais perca inteiramente a consciência dos paradoxos que lhe fazem sentido (RANCIÈRE, 2004, p. 9).

Diríamos que, mais que a construção de uma revista, procurávamos organizar e produzir conhecimentos. Esse espaço-revista inventado, tal como livro didático, poderia construir sentidos e significados para a educação-formação docente; talvez uma maneira encontrada para escapar das armadilhas dos livros oficiais, das prescrições dos currículos, da educação utilitarista e voltada às demandas do progresso, de uma escola distante dos prazeres (cuidados de si) e próxima do governo dos outros, dos disciplinamentos e das normatizações de corpos e mentes.

As políticas educacionais oficiais, muitas vezes, estão distantes dos interesses, desejos e necessidades dos/as educadores/as ou até mesmo inexistem; por isso, os professores/as têm buscado diferentes 
caminhos para a formação. Nessa trajetória, negociamos outras políticas de formação. "A política não é exterior às desigualdades [necessidades, interesses, desejos], embora deva mudá-las, a política é também afetada, alterada, flexionada por ela" (BALL, 1994, p. 15).

A publicação das nossas escrituras tem o desejo de ser esse cuidado com a formação e com a qualidade da educação. Todavia, nas vivências cotidianas da sala de aula, nos encontros multidisciplinares ou entre profissionais de diferentes instituições de ensino ou de distintas áreas esse processo se mostra pouco, ainda é quase invisível dentro da estrutura educacional.

Gallo (2004) estabelece um elo entre o texto $A$ escrita de si, de Foucault, e o campo educacional, articulando o cuidado de si/cuidado do outro com uma outra pedagogia. Para o autor, o filósofo usava cadernos (que continham registros de fragmentos de leituras e de coisas ouvidas) e cartas (trocadas entre conhecidos, amigos, parentes) como possibilidade de investigar as formas de produção de subjetividades. As escrituras dos cadernos e das cartas trocadas (lidas e escritas) foram tratadas como um cuidado de si e um cuidado do outro.

Se o sentido de quem somos está construído narrativamente, em sua construção, em sua formação, terão um papel muito importante as histórias que escutamos e lemos [e também as histórias que escrevemos] assim como o funcionamento dessas histórias no interior de práticas sociais mais ou menos institucionalizadas como, por exemplo, as práticas pedagógicas (LARROSA, 2003, p. 146).

Ao criarmos a revista Apontamentos, corremos o risco de ter prejuízo econômico com o investimento, o que acabou ocorrendo, entretanto isso foi compensado com o prazer da sua elaboração e divulgação. Essa investida iria permitir novas perspectivas e percepções?

Muitas vezes, as pesquisas acadêmicas têm como premissa um produto vinculado à obtenção de grau acadêmico - mestrado, doutorado -, com prazos e formas bem-definidos. Uma condição de modulação política pouco postulada no próprio conhecimento. Na criação da revista, e na sua experiência curricular, estivemos longe dessas obrigações, mais abertos para os processos imprevisíveis e múltiplos, sem data para finalizar, o tempo tornou-se cotidiano. Embora isso possa ser considerado uma vantagem, por outro lado, trabalhar dentro de prazos e limites tem exigi- 
do e potencializado outras formas de responder às demandas educacionais. Mas é provável que a multidirecionalidade e a abertura para as alteridades, esse ir constituindo-se que caracteriza o processo educativo, precise de mais tempo que os postos na maioria dos processos investigativos.

Ao teorizar sobre metodologia buscamos uma relação ontológica entre educação e pesquisa, considerando as relações de poder nas práticas de significação e suas influências na subjetivação. Alguns novos paradigmas de investigação em educação têm sido relatados, muitos deles têm se preocupado com o que vimos nos referindo como mediatização, sobre a questão da legitimidade de representação dos sujeitos.

A perspectiva teórica aqui utilizada desestabiliza as separações arbitrárias de origem elitista ou etnocêntrica. Tal ancoragem, modulada na noção de cultura relativizada, sistematiza vigorosamente, em diferentes ênfases, pesquisa e educação - junto à formação cotidiana. Também concebe na educação um estudo reflexivo e criativo em processo, para assim projetar e praticar a qualificação curricular. Contudo, entendemos que seria uma cilada percorrer um caminho impulsionado por uma crítica linear e reativa, primeiro porque a perspectiva a ser abandonada só seria homogênea por uma viciosa ilusão paradigmática, segundo, por sua politicidade equivocada, negando as forças que julga concentradas num outro, ilegítimo, aético; deixaria de perceber em si o "quanto" desse poder, o como desse poder, que o constituiu e o constitui.

Nesse sentido, um suposto paradoxo tem perdurado nas instituições: a "tradição moderna". Uma recorrente tentativa de tudo controlar e saber. Não raras vezes, desfazendo o que julga passado e prescrevendo o novo. Haveria mesmo algo de reincidente nisso? Construindo uma imagem poética e satírica, o educador Jorge Larrosa chama a atenção para a saturação das interpretações iluminadas, na cultura verbal (ou tradição escrita) e nos lugares institucionais, afinal

$\mathrm{Na}$ Casa do Estudo, onde estão todos os livros, também se fala constantemente dos livros. Os-que-conhecem-os-livros falam e falam, sem cessar, dos livros. E na Casa do Estudo existe quase tantos sábios quanto estantes. Junto a um livro sempre existe alguém que-conhece-o-livro. Por isso, os livros estão previamente lidos, esclarecidos, iluminados. Os livros não têm margens, ou as margens estão cheias de palavras sábias que saturam o texto. Não há espaço entre as linhas, ou os espaços já foram ocupados pelos comentários sábios. Não há vazios entre as palavras, entre as letras. E o estudante pergunta-se como fazer para converter os livros em desconhecidos, como devolver a eles 
seu mistério. Por que, caso contrário, onde o estudante iria encontrar um lugar? (LARROSA, 2003, p. 203)

Parece pertinente pensar esse trecho sem fazer divisões de nível (básico ou superior) na educação, como parece desafiador e produtivo, pensar a educação, e a produção de conhecimentos, reagindo às setorizações e compartimentalizações, sem perder a alegria de criar. Como estudar as influências do pertencimento institucional em relação à validade do conhecimento, se essa dimensão não for fluidificada no currículo?

Poderia uma pesquisa se constituir sem se "saber" pesquisa? Poderia um estudo se constituir estudo sem se "saber" estudo? Seriam possíveis percursos que, sem se saber produtores de conhecimentos, se lançariam à experiência dentro de um campo como a educação, consagrado à construção de conhecimento, mesmo que pouco reconhecido como sistematizador, analítico e inovador? Ou ainda, mover-se por querer atritos, fluidez e porejamentos na tradição profissional - que tem se pautado por desconsiderar a posição de estudante e, concomitantemente, o processo de subjetivação? As/os profissionais-estudantes devem cumprir sua trajetória delineada em um currículo inerentemente setorizado e pouco flexível?

Larrosa cria uma alegoria de um estudante diante do seu tempo, uma possibilidade, dentro das condições de possibilidade "dadas", e mais uma vez, vale a sugestão de pensar esse/a estudante se afastando das categorias habituais, nível acadêmico, idade, gênero, sexo, etnia, classe, etc. Uma experiência de abertura agora simbolizada pelo silêncio, que não é esse calar intimidado que se produz quando o poder é hegemônico:

O silêncio que o estudante conserva é o respeito para com a palavra, a delicadeza para com a palavra. E, por isso, o estudo exige fazer calar rotinas que, se sobrepondo às palavras, matam o silêncio que a palavra ainda contém. $O$ silêncio do estudante é um exercício de ascese [cuidado de si]. Um tipo de desprendimento de toda essa verborragia. (...) o silêncio do estudante é atenção e pureza, escuta e recolhimento. $\mathrm{O}$ estudante quando estuda, cala. Não põe constantemente, como o homem moderno, o alvoroço de sua pessoa e de sua cultura (LARROSA, 2003, p. 203).

Diante de um tempo consagrado à informação e ao consumo, onde uma minoria acumula e se esforça em dominar, o que se poderia fazer além de ter uma posição ontológica, espontânea e naturalizada? Ou, 
ainda, uma presença diametralmente reativa, na qual passa a se acreditar num estereótipo de inimigo? O/a "personagem" aqui apresentado cultua o silêncio, a suspensão interessada, como possibilidade de abertura e cuidado. Esse/a estudante,

O que faz, melhor dizendo, é fazer calar sua pessoa e sua cultura, na medida em que podem pôr a perder o silêncio que envolve a palavra. E estudante tem que fazer calar tudo àquilo que em sua pessoa, nessa arrogante instituição chamada "indivíduo pessoal", poderia acabar com o silêncio. E tem que fazer calar também tudo aquilo que em sua cultura, nessa arrogante instituição dos que sabem, chamada cultura, existe respostas mecânicas e repetitivas, de um falar de acordo com o que está estabelecido, que recobre e satura e exclui o silêncio da palavra com a imposição de uma série de esquemas convencionais de interpretação (LARROSA, 2003, p. 203).

Assim, o cuidado e o conhecimento de si seriam processos poéticos/criativos e reativos do/no presente herdado, não buscariam uma natureza humana perdida ou combater um "inimigo estrangeiro", um ponto em que o poder fosse localizado e destruído. Tampouco existiriam representações e conceitos, compreendidos como subjetivadores externos, como a modernidade ou o capitalismo.

$\mathrm{Na}$ intenção e no desejo de produzir um conhecimento tensionado pela dimensão cultural, através de registros publicados e de sua reelaboração no/sobre/pelo currículo, fez-se necessário vivenciar e analisar uma invenção que foi se desenhando como pesquisa e educação. Se os movimentos necessitaram ser reativos aos cânones, aos estatutos e normatizações, não deveriam se concentrar em "leis de causa e reação" ou substituir por uma anarquia metodológica. Nesse processo, a noção de etapas sequenciais, baseadas em princípio, meio e fim, embora o tempo parecesse cursar assim, mostravam-se concomitantes, em diferentes ênfases. Enquanto essa construção ganhava nitidez e segurança, desejava-se redirecionar as forças para a criatividade, à poiesis. Uma convicção político-pedagógica, em que a subjetivação poderia acontecer modulando o poder que historicamente tem se aglutinado.

Portanto, criou-se um artefato que presencia a sistematização e a não dissociação geográfica da teoria e prática. Teorização que ganha credibilidade quando também afirma ser possível agir em esferas próximas ou mais globais, produzir cultura, saberes e conhecimentos. 
Ainda convém dizer, de outra forma, que este atuar no presente, nas suas circunstâncias contraditórias, não quis se resumir em fazer um movimento contrário e denunciador, como se pudéssemos substituir poderes localizados por nossos projetos mais justos, e, sim, ressignificar, desapropriar, manter a vitalidade da educação. Podemos afirmar que um dos produtos desse processo é o próprio processo e o presente texto, é a revista, que, folheada se organiza em várias formas. Com nova roupagem, tem ido aos congressos. Não haveria conteúdos pretendidos, separados das formas, da estética e de seu constituir, mas sim uma escritura amalgamada de tempos e deslocamentos.

Não é objetivo aqui dar conta das diversas experiências inovadoras em educação, mas poderíamos sugerir que já não é muito raro que novos caminhos podem ser orientados, na perspectiva de se praticar o currículo como processo político e pedagógico, que, por resistir a ser mediatizado, cria e traz na sua tessitura a relação saber-poder, um conhecimento cultural.

Uma tradição leve e intensa de subjetivação, cuidar e conhecer, formas de viver o presente em que as gerações, sempre em formação, valorizam-se como estudantes ao longo de suas vidas. Se a constituição da existência não pode se enquadrar na "expectativa" institucional ou tampouco esperar a espontaneidade-adequação de cada geração diante de seu tempo, o impasse parece se encaminhar para essa tradição leve. Sem apostar em sua destruição como um elemento monolítico, buscar leveza na cultura, fluidez e criação.

\section{Últimas palavras sobre a revista}

Pode ser que a revista inexista para os currículos prescritos, oficiais ou para os padrões internacionais de publicações, no entanto, toda vez que voltamos a ela, (re)significamos nossas ações e acabamos por refazer esse espaço-tempo necessário e contraditório.

Dessa forma, a revista impressa como experiência curricular, como prática social de linguagem, analisada no seu decorrer, se constituiria por meio de sua concepção política, em conhecimento cultural.

O processo de reunião de artigos e seu ir e vir, no currículo, nos congressos, a partir de profissionais de escolas públicas do ensino básico, 
de certa forma, aproximou docentes de diferentes instituições e áreas do conhecimento. Produziu um espaço de publicação, de pesquisa, de registro, de histórias, experimentações, desejos de corte, ruptura com as rotinas, com as repetições do mesmo (mesmo currículo, mesmo conteúdo, mesmas palavras).

Inventou um tempo de dialogar, construir e escrever juntos, em conjunto, de muitas formas, de forma incomum, movimentando fronteiras. Com um pensar que teima/acredita se mostrar/tornar aberto, possível e passível de imaginar-se compondo com outros/as.

O pequeno gesto da revista Apontamentos ajuda a compreender que a educação necessita saber lidar com as contingências, investir centralmente na linguagem, propiciar espaços e tempos de encontros. Enfatiza que os processos, o planejamento, a constituição e a vivência do conhecimento e da cultura podem abalar a hegemonia da produção e do consumismo.

Esse e outros deslocamentos e movimentos do espaço-tempo escolar vêm reforçando o elo da educação com a pesquisa e o entendimento dos/as docentes como intelectuais da educação. Dessa maneira, essas escrituras amalgamadas se apresentaram para muitos sujeitos que a integraram como produção de conhecimento, revisitando a cientificidade, trazendo marcas das esferas sociais e culturais transitadas; os rastros das significações resistindo às heranças autocráticas. Buscamos, assim, resistir e compor registros, protestar credibilidade, nos tensionamentos, nos sempre político-pedagógicos jogos de significação. 


\section{Referências}

BALL, S. J. Education reform: a critical and post-structural approach. Buckingham: Open University, 1994.

FOUCAULT, M. O Sujeito e o Poder In DREYFUS, H.; RABINOW, P. Michel Foucault: uma trajetória filosófica (para além do estruturalismo e da hermenêutica). Rio de Janeiro: Forense Universitária, 1995.

FOUCAULT, M. A hermenêutica do sujeito. São Paulo: Martins Fontes, 2006.

GALLO, S. Repensar a educação: Foucault: Dossiê Michel Foucault. Educaşão e Realidade, Porto Alegre, v. 29, n. 1, jan.-jun. 2004.

GIROUX, H. A.; MCLAREN, P. Formação do professor como uma contra-esfera pública: A pedagogia radical como uma forma de política cultural. In: MOREIRA, A. F.; SILVA, T. T. da (Org.). Currículo, Cultura e Sociedade. São Paulo: Cortez, 2002.

GOODSON, I. F. Currículo: teoria e história. Petrópolis: Vozes, 1999.

LARROSA, J. Pedagogia profana: danças, piruetas e mascaradas. Trad. Alfredo Veiga Neto. Belo Horizonte: Autêntica, 2003.

RANCIÈRE, J. O mestre ignorante: cinco lições sobre a emancipação intelectual. Belo Horizonte: Autêntica, 2004.

SECRETARIA DE EDUCAÇÃO DO RIO GRANDE DO SUL. Cadernos da Constituinte Escolar. Porto Alegre: Corag, 1999.

SECRETARIA DE EDUCAÇÃO DO RIO GRANDE DO SUL. Princípios e Diretrizes para a Educação Pública Estadual. Porto Alegre: Corag, 2000.

SILVA, T. T. da. O currículo como fetiche: a poética e a política do texto curricular. Belo Horizonte: Autêntica, 2003.

VIRILIO, P. A Arte do motor. 2 ed. São Paulo: Estação Liberdade, 1996. 


\section{Notas}

1 Título da música "Televisão", Banda Titãs, composição: Arnaldo Antunes, Marcelo Frommer e Tony Belloto. Disco em vinil, título Televisão, de 1985, gravadora: WEA. Disponível em: http://www.titas.net/discografia/. Site acessado em 09 mai. 2012.

2 Aqui nos referimos a um tipo de exercício profissional em que a prática é romantizada e se opõe à teorização, como uma abstração dissociada do mundo.

\footnotetext{
Recebido: $13 / 10 / 2010$

Aprovado: 25/05/11

Contato:

Rua Itaqui, 280

Balneário Cassino

CEP $96205-150$

Cidade do Rio Grande, RS

Brasil
} 